\title{
The Role of Perceived Risk and Trust Propensity in The Relationship Between Negative Perceptions of Applying Big Data Analytics and Consumers' Responses
}

\author{
THI MAI LE*, \\ VNU International School \\ Vietnam National University \\ Hanoi,VIETNAM \\ mailt@isvnu.vn \\ SHU-YI LIAW, \\ Colleague of Management \\ National Pingtung University of Science and Technology \\ Neipu Township, Pingtung County \\ TAIWAN \\ MY-TRINH BUI \\ VNU International School \\ Vietnam National University \\ Hanoi, VIETNAM
}

\begin{abstract}
With the phenomenal growth of Big Data in e-commerce, applying big data analytics brings negative perception for customers, in one way or another. The research on negative perception of applying big data analytics and the role of perceived risk and trust propensity to consumers' responses under applying Big Data analytics is lacking. Therefore, the aims of this study are to analyze the role of perceived risk and trust propensity in the relationship between negative perceptions of applying big data analytics and consumers' responses. A sample of 349 respondents was used in data analysis. The study found out that perceived risk don't act mediate the relationship between negative perception of applying BDA and consumers' responses. Besides, customers' trust propensity was found to moderate the relation of negative perception of applying BDA to customers' responses and perceived risk to customers' responses. High trust propensity participants reported stronger responses than those with low trust propensity. It due to customers' trust on new applications of BDA, hence, it is easy to influence on customers as their negative response when negative perception and perceived risk are rising. The findings of this research will have implications for e-vendors to understand the important role of perceived risk and trust propensity on customers' responses under Big Data analytics era.
\end{abstract}

Key-Words: - E-commerce, Big Data analytics, perceived risk, trust propensity, customers' responses

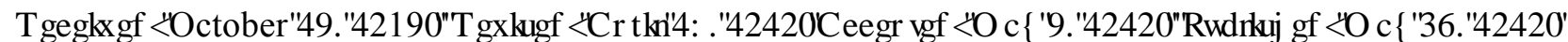

\section{Introduction}

In the era of Internet of Things (IoT), the internet connected many types of electronic devices for life, contributed to the creation and transmission of data leading to the explosion of collectable data. People can create about $2.5 \times 1018$ bytes per day. The acceleration in information production has created the need for new technologies to analyze data sets. The term Big Data refers to data sets that grow rapidly and widely in various forms, making them beyond the capabilities of traditional database systems. Nowadays, big data analytics are used in every sector like as agriculture, energy, health, infrastructure, economics and insurance, sports, tourism and transportation and every world economy. Big Data applications can help organizations; the government predicted the unemployment rate, the future trend for professional investors, or cut spending, stimulates economic growth, etc. Big data has major influence on businesses, since the revolution of networks, platforms, people and digital technology have changed the determinants of firms' innovation and competitiveness. For e-commerce firms, Big Data analytics is used leading their value chain value 5$6 \%$ higher productivity than their competitors [1]. 
The rising expansion of available data is recognized as trend worldwide, while valuable knowledge rising from the information come from data analysis processes. Manyika, Chui [2] defined that Big Data as a dataset with a size that can be captured, communicated, aggregated, stored, and analyzed. Another definition is that Big Data are generated from an increasing plurality of sources including internet clicks, mobile transactions, user generated content and social media as well as purposefully generated content through sensor networks or business transactions such as customer information and purchase transactions [3]. Özköse, Ar1 [4] launched a "5Vs" model that describes 05 important characteristics of Big Data as volume, variety, velocity, veracity and value so it can easily distinguish from the traditional form of data used in analytics. Big data analytics are important and the benefits for data-driven organizations are significant determinants for competitiveness and innovation performance. Specifically, Big Data enables merchants to track each user's behaviour and connect the dots to determine the most effective ways to convert one-time customers into repeat customers in the e-commerce context. E-vendors apply big data analytics will bring positive impacts to customers [5] and it also may bring negative impact to customers. However, the research related to negative effect of big data is lacked. Customers' responses can help a company improve its overall quality of a product or service. It can benefit a customer and a company. The company benefits because it can gather information needed to enhance or correct a product or service. In this study, based on AIDA model, customers' responses can be measured into intention and behaviour stages.

Therefore, this study wants to determine how negative influences of applying BDA to customers' responses in e-commerce context under mediation effect of perceived risk and moderation effect of trust propensity.

\section{Literature Review}

\subsection{Customers' Responses}

A positive consumers' response is a vital intangible asset for an organization and help to grow substantially business either in direct or indirect way. Customers' response was measured in different ways. However, the AIDI model is commonly used in advertising and marketing to illustrate steps that happen from consumers are aware of a product/service before customers try it or giving buying decision [6]. The AIDA (A-Attention, I-Interest, D-Desire, I-Action) is hierarchical model that consumers move through a series of cognitive (thinking) and affective (feeling) stages ending in a behavioural stage (doing e.g. purchase or trial) stage. Under applying application of Big Data analytics, e-vendors will be successful if they can lead their customers to through four stages of hierarchical model as AIDA. Stage one is getting potential customers to their new application by applying BDA. Stage two is creating an interest and demonstrating features and benefits, consumers want to find out more their products or services. Stage three is tirring up a desire to buy that make customers feel it is worth to get the products or use the services. After three stages leads to stage four, customers get to interact directly with the product or service and to take the final decision to end the process. The AIDA model was developed in the 1920 s based on theory of attracting attention, getting interest, motivating desire, and precipitating action. Moreover, the AIDA model was applied to measured customers' resonponse in others studies $[7,8]$. Therefore, the AIDA model is applied to measure consumers' response in this research.

\subsection{The relationship between negative perception of applying BDA and customers' responses}

Negative perception of applying BDA is what customers receive when they have experience with e-vendor under BDA. Negative perception includes privacy and security problem, shopping addiction and group influences. Customers feel uncomfortable and embarrassed when they think that e-vendors know more about them [9]. Guangting and Junxuan [10] said that analyzing the Big Data has negative impact on the consumers' willingness. Negative factors will decrease customers' intention and stimulate their negative behavior, finally drive them to refuse taking action to buy products or services. As discussed above, we propose the following hypothesis:

Hypothesis $\left(\mathbf{H}_{\mathbf{1}}\right)$ : Negative perception of applying Big Data analytics is negatively associated with customers' responses.

\subsection{The Mediating Role of Perceived Risk}

The concept of perceived risk was initially defined it as the feeling of uncertain that the customer has when cannot foresee the consequence of a purchase decision, and comes, since then, being incorporated in researches concerning the consumer behavior. E-commerce industry in Big Data era, perceived risk defined four types: privacy, financial, product performance, psychological, and time risk. Privacy risk, the collection and analytics of Big Data has the potential to consumer privacy concerns. Relevance of personalization gives an 
increasing variety of data sources and context but also carry with them serous privacy problems. Customers are afraid that their information will be used for bad purposes. Time risk is defined as the possibility and the importance of losing time when shopping online. Even with the advantage of shopping all hours, online shopping still raises the time risk because shoppers may experience difficulty navigating websites, submitting orders, and finding appropriate goods [11]. Because Big Data analytics brings many choices for customers but customers can be swim in river of information, spend more time to make purchase decision. Financial risk is defined as the possibility of money loss arises from online shopping. One of the advantages of the Big Data analytics can recommend for customer complementary goods. These complementary goods are appeared after searching the product which they need to buy. They do not intend to buy these products before but after see it, they consider buying it and they will spend more money to buy them. Psychological risk is defined as the possibility that and the importance that the individual suffers emotional stress because of his/her buying behaviour [12]. With searching product and other substitute products which are recommended may lead customers to a lot of choices and if they decide buy one of products, they can face emotional to think back other products.

Market research has reported that the growing concerns about perceived risk associated with online shopping. E-commerce is more applied technology so the concern about perceived risk also will increase. We propose that perceived risk will be positive associated with customer distrust.

Hypothesis $\left(\mathbf{H}_{2}\right)$ : Perceived risk is a mediator of the relationship between negative effect factors of applying BDA and customer's responses.

\subsection{The Moderating Role of Trust Propensity}

Trust is first discussed as a personality trait in Rotter [13]. He mentioned that the propensity to trust is especially important in situations when individuals are working with new people, such as newly-formed buyer-seller relationships. Other researchers distinguished between trust as a situational state and trust as a personality variable [14]. Propensity to trust is a dispositional variable that concerns a person's general willingness to trust others, which is formed through culture, experience, and personality [14]. Trust propensity is also defined as a general tendency or inclination in which people show faith or belief in humanity and adopt a trusting stance toward others $[15,16]$. Trust propensity is not depending on past experiences, but it is on individual orientation. Therefore, the person with propensity to trust tends to expect the best from others and has more optimistic expectations about outcomes. However, Chughtai and Buckley [17] stated that persons with a high propensity to trust believe that most people are sincere, fair, and have good intentions, whereas people who have a low propensity to trust tend to see others as selfcentered, cunning, and potentially dangerous.

Trust propensity is good examples of such moderators [18] and it is researched in various study fields like as human resources [19], online shopping [20-22]. Online consumers with high trust propensity have a higher degree of online initial trust compared to those with a low trust propensity [23].

Trust propensity can be seen as one kind of personal trait; it affects to specific customers' perception to e-vendor. It is a vital factor of customers' responses and other various perceptions about the web site and the company. A strong trust propensity tends to be associated with increased honesty, raise positive feelings and accepting of things at the first sight [24]. Customers with low trust propensity tend to have cautious or even negative views when faced with uncertain situations $[24,25]$. Low trust propensity leads to break customers' desire and reluctance to try new things. Lee and Turban [26] revealed that trust propensity is positively moderator in the relationship between perception about internet vendors to customers' trust in online shopping. However, perceived risk is existence and is threaten that will guide lower consumers' intention to continue to online purchase [20]. Under BDA era brings some negative factors to customers, but good first good feeling from customer will fall quickly when risks are received. Especially, customers with high trust propensity will not think of bad results as the low trust propensity group did. Therefore, we propose that trust propensity is a moderator effect the process from receiving negative factors to customers' responses under mediating of perceived risk.

Hypothesis $\left(\mathbf{H}_{3-1}\right)$ : Trust propensity is a moderator of the relationship between negative perceptions of applying BDA and customers' responses.

Hypothesis $\left(\mathbf{H}_{3-2}\right)$ : Trust propensity is a moderator of the relationship between negative perceptions of applying BDA and perceived risk.

Hypothesis ( $\left.\mathbf{H}_{3-3}\right)$ : Trust propensity is a moderator of the relationship between perceived risk and customers' responses. 
Fig.1 shows the model to evaluate the negative perception of Big Data analytics to customers' responses through mediating effect of perceived risk and moderating effect of customers trust propensity.

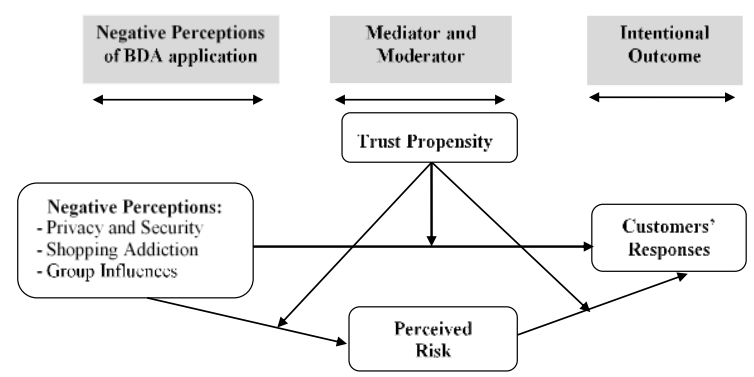

Fig.1 The negative perceptions of BDA to customers' responses under mediating effect of perceived risk and moderating effect of customers trust propensity

\section{Research Methodology}

\subsection{Sample selection}

Data comes from a survey. The respondents have interacted with Amazon website (www.amazon.com) that a famous website using Big Data analytics application. An online survey allows consumers to answer the questionnaire directly after reaction. The respondents have to take a purchase action until the ending the process, but not actually purchase to that item. A sample size of 349 samples was used for analysis. The statistical package for social sciences (SPSS 22.0) and analysis of moment structures (AMOS 22.0) software were used to analyze data. A largest gender group is female $(62.2 \%)$. The majority $(31.2 \%)$ of respondents have experiences each month 1-2 times on website and $18.9 \%$ respondents have no experiences with online shopping. Respondents had interaction with one of two kinds of products are similar percentage, fashion item (50.4\%), electronics item (49.6\%).

\subsection{Measurement}

This section presents the measurement in this research. The measurement variables were used in this research according to related literature. A total 4 constructs were used. First, customers' response was measure by AIDA model in four variables based on $[7,8]$. Second, negative perceptions of applying Big Data analytics was measured on three variables and adopted from previous study $[5,27]$. Third, four validated items were to measure perceived risk taken from the studies Forsythe and Shi [11]; [12]. All items are seven-point Likert-type scales, ranging from (1) strongly disagree to (7) strongly agree. Fourth, trust propensity in this study is measured by using 7 points from low to high trust propensity. Low trust propensity customer means that customer is a difficult person to trust a new thing. In contrast, high trust propensity customer means that customer is an easy person to trust a new thing.

We separated 349 respondents into two groups: Low and high trust propensity based on standardized value of trust propensity to define High and Low risk. The standardized value higher than 0 , it belongs to high trust propensity group. In contrast, the standardized value less than 0 , it belongs to low trust propensity group. Among all respondents, 144 respondents belong to low trust propensity and 205 respondents belong to high trust propensity.

\section{Results and Discussion}

Data analysis proceeded in a three-stage analytical procedure. Firstly, measurement model was done by a confirmatory factor analysis. Next, the structural model and Sobel test for testing mediation were examined. Finally, the moderating effect of trust propensity is explored.

\subsection{Measurement Model}

The assessment of the measurement model for reflective constructs included an estimation of internal consistency for reliability, as well as tests for convergent and discriminant validity [28]. Internal consistency was calculated using Crobach's alpha and Fornell's composite reliability (CR). It is suggested that Crobach reliability coefficients be higher than a minimum cutoff score of 0.70 . Composite reliability (CR) higher than 0.70 is considered adequate. Average variance extracted (AVE) greater than 0.50 indicated that more than $50 \%$ of the variance of the measurement items can be accounted for by the constructs [29]. Discriminant validity was checked by examining whether the correlations between the variables were lower than the square root of the average variance extracted. The results from analysis show that all standardized factor loadings were ranged from 0.700 to 0.934 which are above the recommended value 0.70 according to Hair [29]. The CR and AVE value ranged from 0.857 to 0.899 and 0.600 to 0.809 , respectively, passing their recommended levels. Hair [29] stated that the estimates of CR and AVE should be higher than 0.700 and 0.500 , respectively. Discriminant validity is established using the latent variable correlation matrix, which has the square root of AVE for the measures on the diagonal, and correlations among the measures as the off-diagonal elements (Table 1). Discriminant validity is determined by looking down the columns and across the rows and is deemed satisfactory if the diagonal elements are larger than off-diagonal elements [28]. 
Table 1. The latent variable correlation matrix: Discriminant validity.

\begin{tabular}{llllll}
\hline & M & Std & NP & PR & CR \\
\hline NP & 3.750 & 0.913 & $\mathbf{0 . 8 6 5}$ & & \\
PR & 3.112 & 1.278 & 0.305 & $\mathbf{0 . 7 7 5}$ & \\
CR & 5.633 & 0.817 & -0.201 & -0.103 & $\mathbf{0 . 8 9 9}$ \\
\hline
\end{tabular}

Note: M-Mean; Std - Standard Deviation; Square root of AVE is on the diagonal, Negative perceptions NP; Perceived Risk -PR; Customer Responses -CR.

Table 2 shows the CFA results for measurement model fit indicators. The recommended acceptance of a model fit requires that the obtained goodness of fit index (GFI), the adjusted goodness of fit index (AGFI), the normed fit index (NFI) should be greater than 0.900, the comparative fit index (CFI) should be greater than 0.950 and the root mean square error of approximation (RMSEA) should be less than 0.080 $[30,31]$. The ratio of the chi-square value to degree of freedom is 4.054 which is below recommended value of 5.000. Furthermore, other fit index values for GFI, AGFI, NFI, CFI and RMSEA were 0.941, $0.901,0.944,0.957$ and 0.074 respectively. Those are suitable with recommended values. So that, the measurement model had a good fit.

Table 2. Measurement model fit indicates

\begin{tabular}{llll}
\hline Fit indicates & Criteria & Indicators & Sources \\
\hline DF & $<5.000$ & 4.054 & \\
GFI & $>0.900$ & 0.941 & \\
AGFI & $>0.900$ & 0.901 & {$[32,33]$} \\
NFI & $>0.900$ & 0.944 & \\
CFI & $>0.950$ & 0.957 & \\
RMSEA & $<0.080$ & 0.074 & \\
\hline
\end{tabular}

\subsection{Structural Equation Model}

As shown in Fig.2, the correlation proposed the basic model was confimed. The negative perception has significant negative effect to customers' responses, with coefficient $(\beta=-0.201$, $t=-3.277, p<0.01)$. It means the stronger negative application of applying Big Data analytics, the worse the customers's responses to their behavior. This results is consistent with previous study [34].

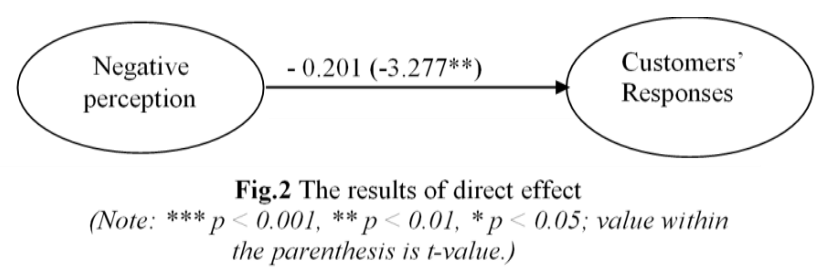

Negative perception includes privacy and security, shopping addiction and group influences which were found that negative effects to customers' responses. In research of Kshetri [9] mentioned that consumers are concerned about potential abuses and misuses of personal data. Especially firms start to collect high-velocity data (e.g. location information (GPS) data from mobile devices click-stream) have met stiff resistance from customers. A 2013 national survey conducted in the U.S. by the Pew Internet \& American Life Project found that $30 \%$ of smartphone owners said that they turned off location tracking features because of concerns that others would access this information (USA Today, 2012). Another project named 2013 Global Consumer under 10.000 consumers found that Privacy of personal data was a "top issue" for $75 \%$. Only $7 \%$ are willing to share their information to be used for purposes other than it was originally collected [35]. Applying BDA can brings some advantages for customers that trational way can not do it. Customers are easy get addiction by spend more time and more finance to buy products with great applications. Besides that customers afraid of other customers review can influence their thinking in negative way.

When adding the mediators (results shown as Fig.3), negative perception decreases its influence, but maintains a significant direct negative effect on customers' response $(c=-0.87, t=-2.942, p<$ $0.01)$. The negative perception has strongly and positive significant effect to perceived risk $\left(a_{1}=\right.$ 0.305, $t=4.971, p<0.001$ ), however then perceived risk has no significant influence on customer's responses $\left(b_{1}=-0.046, t=-0.714\right)$. From the above result, we obtained the Sobel test which indicate z-value, standard error (SE) and $p$-value. The result yields to customers' responses as follow: $z=-0.952$. It results less than $z=1.96$. Therefore, $\mathrm{H}_{2}$ was not supported, indicated that perceived risk is not a mediator in the relationship between negative perception of applying Big Data analytis and customers' responses. 


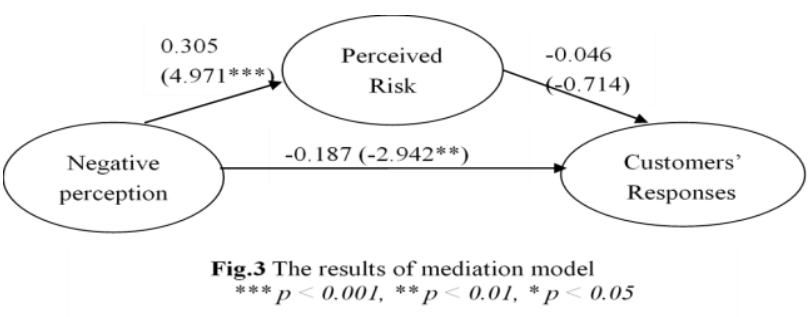

The Sobel test was used to test mediation of perceived risk. As appendix 1 shows, perceived risk is also not a mediator in the relationship between negative perception of applying Big Data analytis and customers' responses with two groups as high trust propensity and low trust propensity $(z=-0.729$ and $z=-0.018$ ), respectively.

\subsection{Examining Moderating Effects}

A summary the results from testing trust propensity as a moderator is provided clearly in Appendix 2 and 3. From the table we can see that the interaction coefficient of negative perception of applying BDA and trust propensity was significant at 0.001 level $(\beta=-0.273, t=-4.916, p<0.001)$, indicating that trust propensity moderated the relationships of negative perception and customers' responses. Hypothesis $\mathrm{H}_{3-1}$ was supported that the moderating role of trust propensity in the relationships of negative perception and customers' responses. Trust propensity is considered as a moderator in previous studies [18, 20, 22]. Besides that, interaction coefficients of perceived risk and trust propensity also significant at 0.001 level $(\beta=$ $0.186, t=3.326, p<0.001)$, indicating that trust propensity moderated the relationships of perceived risk and customers' responses. Hypothesis $\mathrm{H}_{3-3}$ was supported that trust propensity has strong moderating effect in relationship of perceived risk and customers' responses. Before the appearance of trust propensity, perceived risk has negative influence to customers' responses $(\beta=-0.046, t=$ 0.714 ) and not significant effect. But after the appearance of trust propensity, the interaction of perceived risk and trust propensity has significant positive influence to customers' responses $(\beta=$ $0.186, t=3.326, p<0.001$ ).

However, interaction of negative perception of applying BDA and trust propensity was not significant $(\beta=-0.083, t=-1.485)$, respectively. Thus, $\mathrm{H}_{3-2}$ was not supported. It indicates that trust propensity doesn't act as a moderator in the relationship between negative perception and perceived risk.

Under moderating effect of trust propensity, the direct effect of negative perception to customers' responses $(\beta=-0.019, t=-0.317)$ was not significant effect. Due to the influences of interaction between negative perception and trust propensity to customers' response was strongly significant $(\beta=-0.273, t=-4.916, p<0.001)$.

We can see that this negative impact was stronger on high trust propensity group than low trust propensity group, with correlation of -0.20 and -0.133 respectively. As can be seen in Fig.4 differences in simple slopes for low and high trust propensity, though high trust propensity group show a relative higher positive customers' responses than the low trust propensity group, it decreases faster with the rise of negative perception of applying BDA.

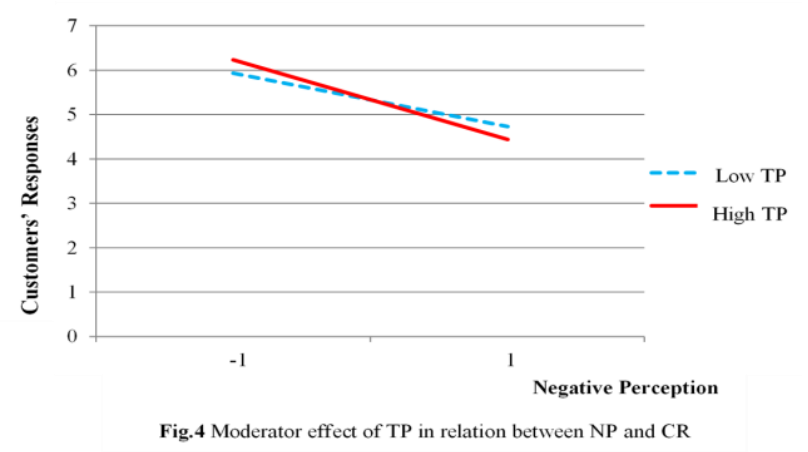

Similarly, the interaction effect of perceived risk and customers trust propensity can be seen clearly in Fig.5. In comparing the effect that perceived risk plays on customers' responses, we can see that this negative influence was stronger on high trust propensity group than low trust propensity group, with correlation of -0.071 and -0.046 , respectively. It can be seen clear from Fig.5 that high trust propensity group initially show a relative higher than the low trust propensity group. However, customers' responses then decrease faster with the rise of perceived risk.

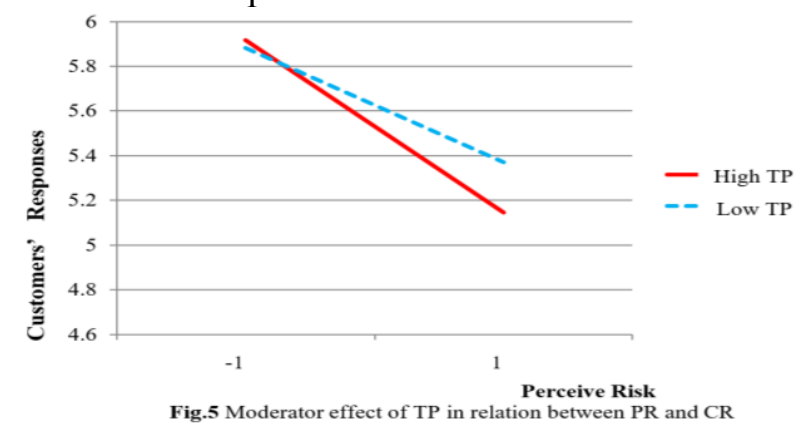

\section{Conclusions}

In this study, we investigate the moderating effect of the perceived risk and the moderating effect of trust propensity regarding the relationship between negative perception and customers' responses. Using collected data, this study first confirmed that perceived risk does not mediate the 
relationship between perceptions of negative perception of applying BDA to customers' responses. This finding is different with the results of existing studies [36, 37]. Negative perception has strongly negative effects to perceived risk but perceived risk doesn't influence to customers' responses. It leads to perceived risk doesn't act as mediator between negative perception of applying BDA and customers' responses. However, under no significant mediation effect of perceived risk, the negative perception keeps negative influences to customers' responses.

This study second confirms that the relationship of negative perception and customers' responses is interrupted by trust propensity. It indicates that high trust propensity participants reported higher customers' responses than those with low trust propensity but this reversed when negative perception was high. Besides that, perceived risk has negative influence to customers' responses and not significant effect. But after the appearance of trust propensity, the interaction of perceived risk and trust propensity has significant positive influence to customers' responses. It means the trust propensity has high impact on the effect of perceived risk to customers' responses. Chen, Yan [20] found that trust propensity is a moderator of the relationship between perceived risk and online consumers' overall satisfaction. The results on moderating effect of trust propensity showed that customers' responses will be low under high negative perception or high perceived risk under applying BDA even customers who have high trust propensity.

There are four academic contributions in this study. First, this study summarizes the notions of negative perception and customers' perceived risk and customers' responses to extend the literature on customers' behaviour under big data era. Second, there is no prior study exploring perceived risk as a mediator and moderating effect of trust propensity in the relationship among negative perception of applying BDA, perceived risk and customers' responses. Third, this study demonstrates that the negative perception of applying BDA has negative influence to customers' responses under no mediation effect of perceived risk in this relationship. Four, this study indicates that trust propensity is perfect moderator of direct effect between negative perceptions to customers' responses.

There are two practical contributions in this study. First, this study verifies that the negative perception of applying BDA has negative influence to customers' responses under no mediation effect of perceived risk in this relationship. If companies would like to enhance positive customers' responses for their products or services, they should decrease negative perception when they apply BDA. Second, trust propensity was shown to moderate consumers' purchase behavior. Trust propensity develops over time and it is individual, in part, a function of social influences. Trust propensity may follow market development condition, especial e-commerce adoption. Different market development conditions may mean that online trust-building mechanisms may be more necessary in one situation than another. Kosinski, Stillwell [38] demonstrated that public records of Facebook users such as click "like" could be used to accurately predict a wide range of sensitive personal attributes including trust propensity, intelligence, sexual orientation, etc. Therefore, it is to worth for Facebook to explore the public records of users that can be explained by the users' propensity to trust. In addition, e-firms are applying BDA could build environment to rise up customers' trust propensity. Hence, this way can reduce the negative effect of negative perception when applying BDA to customers' responses.

BDA methods are applied to large data sets that consist different types of data. The aims are to detect patterns, correlations, trends, and other useful information. Artificial intelligence provides AI algorithms that train data and to learn. AI algorithms can learn and improve their customers' behavior, and includes semantic technologies. Therefore, the combination of Big data analytics and Artificial Intelligent to manage different data sets, understand insights and make predictions

There are some limitations can be obtained from this research and following recommendations for future studies. Firstly, sample respondents were Vietnamese and would be a limitation to the study. However, the contribution of this study is worthy and applicable for developing countries such as Vietnam. Further studies may take a cross-culture comparison between different countries since different culture and level of Big Data analytics. Secondly, the present study used user's views of their response as a dependent variable. Even though users' view is frequently used as a surrogate measure of behaviour, it does not accurately predict actual buying situation. Thus, the results found in the present study should be understood and practiced with caution. Similar future studies should measure to fit in actual online shopping behaviour such as information search, real recorded ordering, and purchase amount as a dependent variable. 


\section{Declaration of Conflicting Interests}

The authors declared no potential conflicts of interest with respect to the research, and or publication of this article.

\section{Funding}

This research is funded by International School, Vietnam National University, Hanoi (VNUIS) under project number KHCN_2019.01

\section{References:}

[1]. McAfee, A., et al., Big data. The management revolution. Harvard Bus Rev, 2012. 90(10): pp. 61-67.

[2]. Manyika, J., et al., Big data: The next frontier for innovation, competition, and productivity. 2011.

[3]. George, G., M.R. Haas, and A. Pentland, Big data and management. Academy of Management Journal, 2014. 57(2): pp. 321-326.

[4]. Özköse, H., E.S. Ar1, and C. Gencer, Yesterday, today and tomorrow of big data. Procedia-Social and Behavioral Sciences, 2015. 195: pp. 1042-1050.

[5]. Le, T.M. and S.-Y. Liaw, Effects of pros and cons of applying big data analytics to consumers' responses in an e-commerce context. Sustainability, 2017. 9(5): pp. 798.

[6]. Gharibi, S., S. Danesh, and K. Shahrodi, Explain the effectiveness of advertising using the AIDA model. Interdisciplinary Journal of Contemporary Research in Business, 2012. 4(2): pp. 926-940.

[7]. Ehrenberg, A.S., Repetitive advertising and the consumer. Journal of Advertising Research, 2000. 40(6): pp. 39-48.

[8]. Lee, T.-R., et al., Managing the positive and negative characteristics of enterprise microblog to attract user to take action through the perspective of behavioural response. International Journal of Management and Enterprise Development, 2013. 12(4-6): pp. 363384.

[9]. Kshetri, N., Big data' s impact on privacy, security and consumer welfare. Telecommunications Policy, 2014. 38(11): pp. 1134-1145.

[10].Guangting, Z. and Z. Junxuan, The Study of Impact of" Big Data" to Purchasing Intention. International Journal of Business and Social Science, 2014. 5(10).

[11].Forsythe, S.M. and B. Shi, Consumer patronage and risk perceptions in Internet shopping. Journal of Business research, 2003. 56(11): pp. 867-875.
[12].Lim, N., Consumers' perceived risk: sources versus consequences. Electronic Commerce Research and Applications, 2003. 2(3): pp. 216228.

[13].Rotter, J.B., Generalized expectancies for interpersonal trust. American psychologist, 1971. 26(5): pp. 443.

[14].Mayer, R.C., J.H. Davis, and F.D. Schoorman, An integrative model of organizational trust. Academy of management review, 1995. 20(3): pp. 709-734.

[15].Gefen, D., E-commerce: the role of familiarity and trust. Omega, 2000. 28(6): pp. 725-737.

[16].McKnight, D.H. and N.L. Chervany, What trust means in e-commerce customer relationships: An interdisciplinary conceptual typology. International journal of electronic commerce, 2001. 6(2): pp. 35-59.

[17].Chughtai, A.A. and F. Buckley, Work engagement and its relationship with state and trait trust: A conceptual analysis. Journal of Behavioral and Applied Management, 2008. 10(1): pp. 47.

[18].Li, N. and P. Zhang, What makes customers shop online. Electronic Customer Relationship Management. Advances in Information Management Systems, 2006. 3: pp. 149-176.

[19].Poon, J.M., A.H. Mohd Salleh, and Z.C. Senik, Propensity to trust as a moderator of the relationship between perceived organizational support and job satisfaction. International Journal of Organization Theory \& Behavior, 2007. 10(3): pp. 350-366.

[20].Chen, Y., et al., The joint moderating role of trust propensity and gender on consumers' online shopping behavior. Computers in Human Behavior, 2015. 43: pp. 272-283.

[21].Fan, Y.W. and J.C. Chen. The moderating effect of disposition to trust in online services. in The 10th Annual Meeting Asia-Pacific Decision Sciences Institute, Taipei, Taiwan. 2005.

[22].Friend, S.B., J.S. Johnson, and R.S. Sohi, Propensity to trust salespeople: A contingent multilevel-multisource examination. Journal of Business Research, 2018. 83: pp. 1-9.

[23].Chen, Y.-H. and S. Barnes, Initial trust and online buyer behaviour. Industrial management \& data systems, 2007. 107(1): pp. 21-36.

[24].Graziano, W.G. and R.M. Tobin, Agreeableness: Dimension of personality or social desirability artifact? Journal of personality, 2002. 70(5): pp. 695-728.

[25].Falcone, R., M. Singh, and Y.-H. Tan, Trust in cyber-societies: integrating the human and 
artificial perspectives. Vol. 2246. 2001: Springer Science \& Business Media.

[26].Lee, M.K. and E. Turban, A trust model for consumer internet shopping. International Journal of electronic commerce, 2001. 6(1): pp. $75-91$.

[27].Al Mana, A.M. and A.A. Mirza, The impact of electronic word of mouth on consumers' purchasing decisions. International Journal of Computer Applications, 2013. 82(9).

[28].Fornell, C. and D.F. Larcker, Evaluating structural equation models with unobservable variables and measurement error. Journal of marketing research, 1981: pp. 39-50.

[29].Hair, J.F., Multivariate data analysis. 2010, NJ, USA: Pearson College Division.

[30].Maichum, K., S. Parichatnon, and K.-C. Peng, Application of the Extended Theory of Planned Behavior Model to Investigate Purchase Intention of Green Products among Thai Consumers. Sustainability, 2017. 8: pp. 1077.

[31].Tabachnick, B.G., L.S. Fidell, and S.J. Osterlind, Using multivariate statistics. 2001, NJ, USA: Pearson College Division.

[32].Hair, J.F., et al., An assessment of the use of partial least squares structural equation modeling in marketing research. Journal of the academy of marketing science, 2012. 40(3): pp. 414-433.

[33].Hoe, S.L., Issues and procedures in adopting structural equation modeling technique. Journal of applied quantitative methods, 2008. 3(1): pp. 76-83.

[34].Le, T.M. and S.-Y. Liaw, Effects of Pros and Cons of Applying Big Data Analytics to Consumers' Responses in an E-Commerce Context. Sustainability, 2017. 9: pp. 798.

[35].Rose, J., et al., The trust advantage: How to win with big data. BCG Perspective, 2013.

[36].Agarwal, S. and R.K. Teas, Perceived value: mediating role of perceived risk. Journal of Marketing theory and Practice, 2001. 9(4): pp. $1-14$.

[37].Chen, Y.-S. and C.-H. Chang, Greenwash and green trust: The mediation effects of green consumer confusion and green perceived risk. Journal of Business Ethics, 2013. 114(3): pp. 489-500.

[38].Kosinski, M., D. Stillwell, and T. Graepel, Private traits and attributes are predictable from digital records of human behavior. Proceedings of the National Academy of Sciences, 2013. 110(15): pp. 5802-5805.

[39].Lejoyeux, M. and A. Weinstein, Shopping addiction. Principles of addiction. 2013, US: Academic

Press.

$847-853$ 


\section{APPENDIX}

Appendix 1. Mediation effect of perceived risk

\begin{tabular}{lllllllc}
\hline Model & Path & $\boldsymbol{A}$ & $\boldsymbol{S} \boldsymbol{e}_{\boldsymbol{a}}$ & $\boldsymbol{b}$ & $\boldsymbol{S} \boldsymbol{e}_{\boldsymbol{b}}$ & Sobel $-\boldsymbol{z}$ & Hypothesis \\
\hline All TP & $\mathrm{NP} \rightarrow \mathrm{PR} \rightarrow \mathrm{CR}$ & 0.305 & 0.075 & -0.046 & 0.047 & -0.952 & $\mathrm{H}_{2}$ \\
Low TP & $\mathrm{NP} \rightarrow \mathrm{PR} \rightarrow \mathrm{CR}$ & 0.317 & 0.107 & -0.061 & 0.081 & -0.729 & \\
High TP & $\mathrm{NP} \rightarrow \mathrm{PR} \rightarrow \mathrm{CR}$ & 0.294 & 0.107 & -0.001 & 0.055 & -0.018 & \\
\hline
\end{tabular}

Appendix 2. The results of moderating model

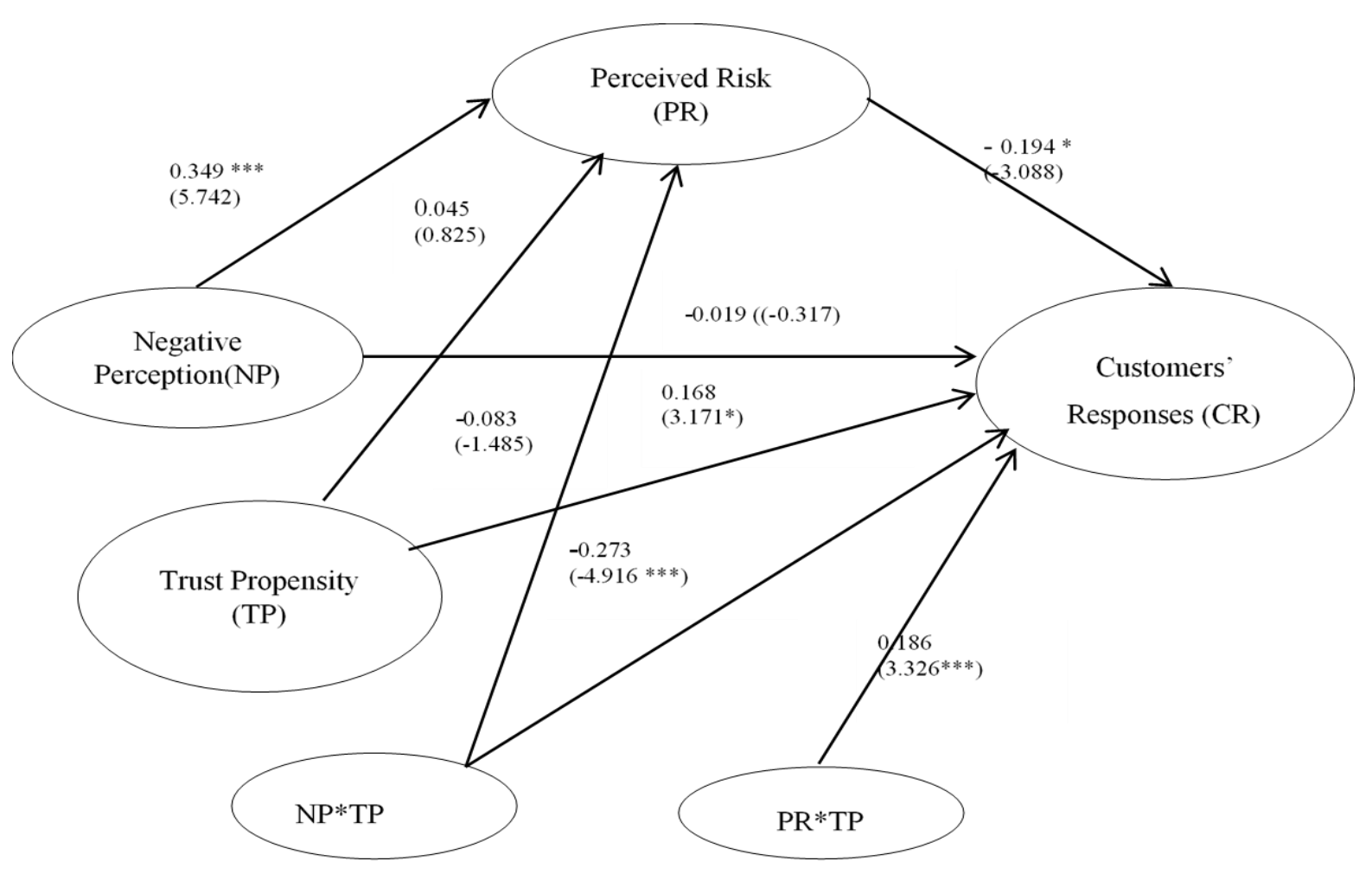

(Note: $* * * p<0.001, * * p<0.01, * p<0.05$; value within the parenthesis is t-value.)

Appendix 3. Relationship between NP and CR, moderator effect by TP

\begin{tabular}{lcccccc}
\hline \multicolumn{1}{c}{ Path } & $\begin{array}{c}\text { Standardized } \\
\text { coefficients }\end{array}$ & \multicolumn{2}{c}{ Unstandardized coefficients } & Hypothesis & Hypothesis \\
& $\boldsymbol{B}$ & $\boldsymbol{\beta}$ & $\mathbf{S E}$ & $\boldsymbol{T}$ & & \\
& -0.019 & -0.017 & 0.055 & -0.317 & & \\
\hline $\mathrm{PP} \rightarrow \mathrm{CR}$ & -0.194 & -0.143 & 0.046 & $-3.088^{*}$ & & \\
\hline $\mathrm{PR} \rightarrow \mathrm{CR}$ & 0.168 & 0.280 & 0.088 & $3.171^{*}$ & & \\
\hline $\mathrm{TP} \rightarrow \mathrm{CR}$ & -0.273 & -0.088 & 0.018 & $-4.916^{* * *}$ & $\mathrm{H}_{3-1}$ & Supported \\
\hline $\mathrm{NP} * \mathrm{TP} \rightarrow \mathrm{CR}$ & 0.186 & 0.057 & 0.017 & $3.326^{* * *}$ & $\mathrm{H}_{3-3}$ & Supported \\
\hline $\mathrm{PR} * \mathrm{TP} \rightarrow \mathrm{CR}$ & 0.349 & 0.437 & 0.076 & $5.742^{* * *}$ & & \\
\hline $\mathrm{NP} \rightarrow \mathrm{PR}$ & 0.045 & 0.102 & 0.123 & 0.825 & & \\
\hline $\mathrm{TP} \rightarrow \mathrm{PR}$ & -0.083 & -0.036 & 0.024 & -1.485 & $\mathrm{H}_{3-2}$ & Not Supported \\
\hline $\mathrm{NP} * \mathrm{TP} \rightarrow \mathrm{PR}$ & & & & & & \\
\hline
\end{tabular}

Note: $* p<0.05, * * p<0.01,{ }^{* * *} p<0.001 ; N P=$ Negative perceptions, $P R=$ Perceived Risk, $T P=$ Trust Propensity, $C R=$ Customers' Responses 